\title{
biomolecules
}

ISSN 2218-273X

www.mdpi.com/journal/biomolecules/

Review

\section{Inhibition of Topoisomerase (DNA) I (TOP1): DNA Damage Repair and Anticancer Therapy}

\section{Yang Xu and Chengtao Her *}

School of Molecular Biosciences, College of Veterinary Medicine, Washington State University, Mail Drop 64-7520, Pullman, WA 99164, USA; E-Mail: davidxy22@vetmed.wsu.edu

* Author to whom correspondence should be addressed; E-Mail: cher@wsu.edu; Tel.: +1-509-335-7537; Fax: +1-509-335-4159.

Academic Editors: Wolf-Dietrich Heyer, Thomas Helleday and Fumio Hanaoka

Received: 22 May 2015 / Accepted: 14 July 2015 / Published: 22 July 2015

\begin{abstract}
Most chemotherapy regimens contain at least one DNA-damaging agent that preferentially affects the growth of cancer cells. This strategy takes advantage of the differences in cell proliferation between normal and cancer cells. Chemotherapeutic drugs are usually designed to target rapid-dividing cells because sustained proliferation is a common feature of cancer [1,2]. Rapid DNA replication is essential for highly proliferative cells, thus blocking of DNA replication will create numerous mutations and/or chromosome rearrangements - ultimately triggering cell death [3]. Along these lines, DNA topoisomerase inhibitors are of great interest because they help to maintain strand breaks generated by topoisomerases during replication. In this article, we discuss the characteristics of topoisomerase (DNA) I (TOP1) and its inhibitors, as well as the underlying DNA repair pathways and the use of TOP1 inhibitors in cancer therapy.
\end{abstract}

Keywords: topoisomerase (DNA) I (TOP1); anticancer therapy; DNA replication; topoisomerase inhibitor; DNA double-strand break (DSB); DSB repair; homologous recombination (HR); non-homologous end joining; single-strand break (SSB) repair; one-ended DSB 


\section{Type IB Topoisomerases and Inhibitors}

\subsection{TOP1}

DNA topoisomerases resolve topological constraints that may arise from DNA strand separation and are therefore important for transcription and replication [4]. There are six topoisomerases in humans, classified as Type IA, IB and IIA. Type IA topoisomerases TOP $3 \alpha$ and TOP $3 \beta$ cleave one DNA strand to relax only negative supercoiling. In addition, TOP $3 \alpha$ forms the BTR complex with BLM and RMI1/2, which plays a role in the dissolution of double-Holliday junctions [5]. Type IIA topoisomerases TOP $2 \alpha$ and TOP $2 \beta$ generate double-strand breaks on one DNA molecule to allow the passing of other DNA strands [6]. Topoisomerases are attractive drug targets in cancer therapy. For example, the commonly used anticancer agents doxorubicin and etoposide (VP-16) are TOP2 inhibitors [7]. Type IB topoisomerases include the nuclear TOP1 and mitochondrial TOP1mt [4]. TOP1 initiates the DNA relaxation by nicking one DNA strand. It then forms a TOP1-DNA cleavage complex (TOP1cc) by covalently linked to the 3'-phosphate end via its tyrosine residue Y723 (3'-P-Y). Following the resolution of topological entanglements and the removal of TOP1, the 5'-hydroxyl end is realigned with the 3'-end for religation. Each nicking-closing cycle enables the relaxation of one DNA supercoiling (Figure 1).

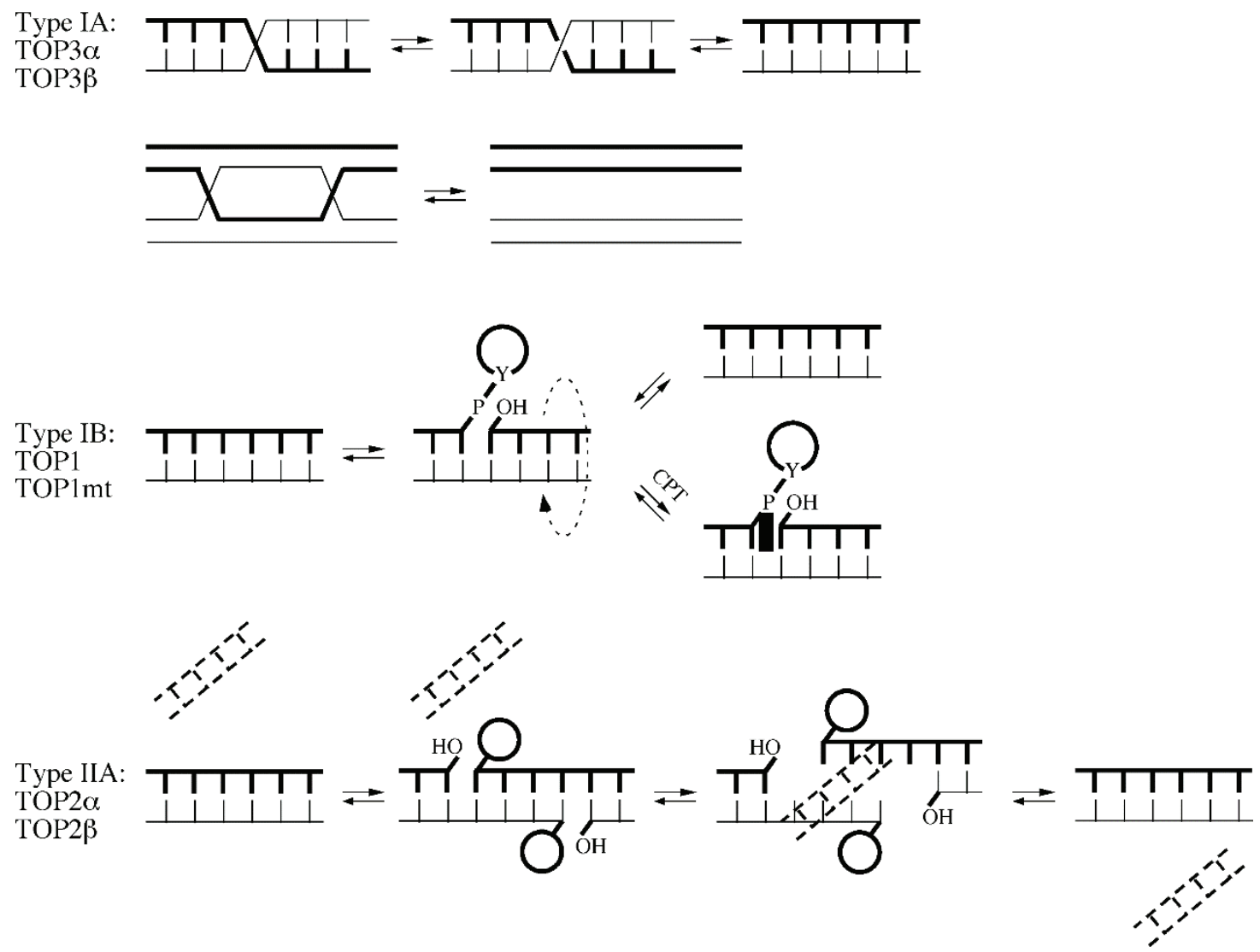

Figure 1. A schematic representation of strand passages catalyzed by three types of topoisomerases (adapted from ref. [8]).

TOP1 is essential for embryonic development in mammals [9]. Although TOP1 plays an important role in the deconvolution of supercoils arising amid DNA replication, the precise steps involved with 
the recruitment of TOP1 to topological constraints remains to be revealed. It appears that in yeast TOP1 travels at a distance of $600 \mathrm{bp}$ ahead of the replication fork [10] and remains associated with the GINS-MCM complex [11]. However, the yeast TOP1 is distinct from its human counterpart in that it has little effect on fork progression or the firing of replication origin [12]. In humans, TOP1 binds to the regions of the pre-replicative complex in cells during the $\mathrm{M}$, early $\mathrm{G} 1$, and $\mathrm{G} 1 / \mathrm{S}$ phases of the cell cycle to control the firing of replication origins [12]. This difference may explain why yeast cells are viable in the absence of TOP1. In addition, TOP1 also has functions in transcription that are independent of its role in resolving DNA topological entanglements. First, TOP1 is known to repress transcription by binding to TFIID [13]. Second, inhibition of TOP1 can cause the induction of c-Jun in leukemia cells, suggesting its additional role in the control of transcription [14]. Furthermore, TOP1 interacts with the splicing factor ASF/SF2 by which it promotes the maturation of RNA - through suppressing the formation of R-loops (RNA-DNA hybrids) - and prevents collision between transcription bubble and replication fork $[15,16]$. It appears that the levels of TOP1 have to be dynamically regulated. In B cells, TOP1 is reduced by activation-induced cytidine deaminase (AID) to facilitate class-switch recombination (CSR) and somatic hypermutation (SHM) [17,18]. Although TOP1mt is important for mitochondrial integrity and metabolism, mice lacking mitochondrial TOP1mt are viable and fertile but they are associated with increased negative supercoiling of mtDNA [19,20].

\subsection{TOP1 Inhibitors}

Stabilization of TOP1cc by topoisomerase poison is detrimental to cells due to the disruption of DNA uncoiling, increased strand breaks, and unstable RNA transcripts as well as incomplete DNA replication [21]. The TOP1 inhibitor camptothecin (CPT), first isolated from the Chinese tree Camptotheca acuminate, was clinically used for cancer treatment long before it was identified as a TOP1 inhibitor [22]. Due to side effects, CPT is no longer used clinically and it has been replaced by more effective and safer TOP1 inhibitors [23]. Currently, CPT derivatives topotecan (trade name: Hycamtin) and irinotecan (CPT-11, trade name: Camptosar) are routinely used to treat colorectal, ovarian and lung cancers, while a few other TOP1 inhibitors are being tested in clinical trials.

CPT is a 5-ring alkaloid that is active in its closed E-ring (lactone) form but it is inactive with an open E-ring (carboxylate) at physiological and alkaline $\mathrm{pH}$ [24]. Therefore, CPT is not effective for inhibiting TOP1mt due to a higher $\mathrm{pH}$ mitochondrial environment. The inactive form of CPT tends to bind to serum albumin, which might be a reason for its side effects. CPT is highly specific for TOP1 and the binding is of relatively low affinity and can be reversed after drug removal. These features make the action of CPT controllable [24], and in fact CPT is widely used in studies of replication-associated DNA damage response. There are a few CPT derivatives and non-CPT TOP1 inhibitors $[4,8,24]$. For example, CPT derivatives Diflomotecan and S39625 were designed to stabilize the E-ring. Irinotecan has the bis-piperidine side chain to increase its water solubility, but it also contributes to some side effects. Non-CPTs — such as indolocarbazoles, phenanthrolines (e.g., ARC-111) and indenoisoquinolines - refer to drugs that have no typical CPT E-ring structures but they can still specifically target TOP1 and bind irreversibly to TOP1cc. Some of the CPT derivatives (i.e., Gimatecan and Belotecan) and non-CPTs (i.e., NSC 725776 and NSC 724998) are presently tested in clinical trials [23]. 
How does CPT trap TOP1cc? Analysis of the crystal structure and modeling suggest that CPT-TOP1-DNA forms a ternary complex to prevent the two DNA ends from religation [25-27]. Although it is still controversial on how CPT is intercalated into DNA, it seems that CPT traps TOP1cc with a thymine $(\mathrm{T})$ at the -1 position and a guanine $(\mathrm{G})$ at the +1 position on the scissile strand, and it is therefore sequence-specific [28]. Three amino acid residues of the TOP1 enzyme, R364, D533 and N722, combined with DNA bases, contribute to the stabilization of the ternary complex by forming hydrogen bonds and hydrophobic interactions. It is of note that several point mutations, including N722S, in Camptotheca acuminata TOP1 confer resistance to CPT [29]. Interestingly, the same amino acids also contribute to the inhibition of TOP1 by non-CPT drugs [24].

\section{Repair of TOP1 Poison-Induced DNA Lesions}

As aforementioned, CPT-induced trapping of TOP1cc creates a single strand break with a free 5'-hydroxyl group, whereas the 3'-phosphate is connected to Y723 of TOP1 (3'-P-Y). At least two pathways contribute to the repair of DNA lesions created by TOP1 poison [30]. The tyrosyl-DNA-phosphodiesterase (TDP1) pathway starts with the ubiquitination and proteasome-mediated degradation of TOP1 in the CPT-TOP1-DNA complex to generate a 3'-P end linked to a short peptide [31]. TDP1 then cleaves the P-Y bond to release the 3'-P end; however, the 3'-P end cannot be directly ligated to the 5'-OH end because of the requirements of DNA ligases. The human polynucleotide kinase (PNKP) can process the DNA ends by functioning as both a 3'-phosphatase and a kinase to generate the required 3'-OH and 5'-P termini for direct ligation. The rest of the repair events can be best described by the single-strand break (SSB) repair pathway, which will be discussed below. Indeed, TDP1 and PNKP are tightly associated with the SSB repair machinery $[32,33]$.

The endonuclease pathway requires multiple endonucleases to excise the DNA- usually at a few nucleotides away from the 3'-P-TOP1 end - on the scissile strand to release the DNA-TOP1 complex [30]. Initial studies were carried out to identify genes that functioned in CPT repair in the absence of TDP1 in yeast $[34,35]$. These studies led to the identification of RAD1-RAD10, SLX1-SLX4, MUS81-MMS4, MRE11-SAE2 as well as genes involved in recombination. The RAD1-RAD10 (human XPF/ERCC4ERCC1) complex is a DNA structure-specific endonuclease that can act on 5' overhang structures [36]. Interestingly, the cleavage site of XPF-ERCC1 is in the non-protruding DNA strand, about 3-4 nucleotides away from the $3^{\prime}$ end [36]. Therefore, trapped TOP1ccs can be removed by this endonuclease activity. Likewise, MUS81-MMS4 (human MUS81-EME1) can also cleave nicked duplex at the 5' of the nick [37]. The SLX1-SLX4 endonuclease, although not tested on nicked duplexes, is able to process 3' flap and other DNA structures [38,39]. In human cells, SLX4 also associates with XPF-ERCC1 and MUS81-EME1 endonucleases to process specific DNA intermediates [39,40]. Moreover, MRE11-RAD50 cleaves the 3'-P-Y bond and resects DNA to produce a 3'-OH end [41]. A direct role of SAE2 (human CtIP) in processing 3 '-P-TOP1 is unknown, and its endonuclease activity appears to be limited to the 5 ' flap or DNA "hairpin" structures $[42,43]$. Nonetheless, the endonuclease activity of CtIP is essential for processing CPT adducts [42]. In addition, like CtIP, the 5' flap endonuclease RAD27 (human FEN1) seems to be unable to directly process 3'-P-TOP1 ends [44]. However, the gap endonuclease activity of FEN1 is important for processing stalled replication forks and CPT-induced adducts [45]. The role of FEN1 in SSB repair will be discussed further in the next section. 
During DNA replication, SSBs created by CPT are most likely converted to double-strand breaks (DSBs) by replication fork runoff. This conversion appears to be dependent on the proteolysis of TOP1 [46]. The repair of one-ended DSBs, as will be discussed in the next section, is largely dependent on homologous recombination (HR). However, low doses of CPT may also induce PARP1 and/or RAD51 dependent replication fork regression-generating no or few DSBs [47,48]. The regressed fork leads to the formation of a "chicken foot" DNA structure by newly synthesized strands $[3,49,50]$. The formation of regressed fork can be largely suppressed by ATR, EXO1, and DNA2 [51-53]. However, fork reversal can also be beneficial as it provides time for the repair of TOP1-induced DNA lesions by TDP1, thereby preventing DSB formation and the activation of error-prone non-homologous end-joining (NHEJ) [30].

\section{Pathways Involved in the Repair of CPT-Induced DNA Lesions}

Normal cells use DNA damage response (DDR) pathways to maintain genomic stability [54]. As aforementioned, SSB and DSB repair mechanisms are the two major DDR pathways that repair TOP1-induced DNA lesions. Paradoxically, cancer cells exploit DDR pathways to accumulate necessary genomic alterations for promoting proliferation. Furthermore, altered DDR and apoptotic responses in cancer cells are the major obstacles to successful chemotherapy. Thus, the delineation of TOP1-related SSB and DSB repair mechanisms is of great importance for identifying drug targets that can selectively affect cancer cell survival.

\subsection{Single-Strand Break (SSB) Repair}

Trapping of TOP1cc results in a 3'-P-TOP1 end and a 5'-OH terminus. Because the two ends cannot be directly religated, the persisting SSB is likely to be detected by PARP1 in which activated PARP1 catalyzes the synthesis of poly(ADP-ribose) (PAR) chains for recruiting repair proteins [55]. This reaction can be rapidly reversed by PARG, which hydrolyzes the PAR chains. The PAR chains at the SSB sites are important for the recruitment of XRCC1 that functions as a loading dock for other SSB repair proteins including TDP1 and PNKP. TDP1 generates 3'-P and PNKP converts 3'-P to 3'-OH, and PNKP also converts 5'-OH to 5'-P, making ends compatible for religation with no base loss. The rejoining of the 3'-OH and 5'-P ends is mainly mediated by LIG3, in which XRCC1 mediates the recruitment of LIG3.

If the trapped TOP1cc intermediates are processed by endonucleases, the initial SSBs will be converted to 3'-OH and 5'-OH ends with a gap over a few nucleotides (in the case of XPF-ERCC1, the loss is in the range of 3-4 nt), leading to the activation of PARP1 and XRCC1 recruitment. Consequentially, Pol $\beta$ recruited by XRCC1 can catalyze the gap filling, and PCNA-Pol $\delta / \varepsilon$ also plays a role in this process [55]. If the 5'-OH is not processed by PNKP, the 5'-flap resulted from gap filling is likely to be removed by FEN1, which explains why FEN1 deficiency also leads to an increased CPT sensitivity. The final ligation is catalyzed by LIG1 because of the presence of PCNA. 


\subsection{Double-Strand Break (DSB) Repair}

Successful DSB repair requires concerted actions of proteins involved in DNA damage signaling and repair [54]. To repair TOP1 poison-induced DNA lesions, ATR signaling is required due to the runoff of replication fork and the presence of long single-strand DNA (ssDNA) [56]. The full activation of ATR follows a "two-man" rule-the ssDNA-ATRIP-dependent recruitment of ATR kinase and the RAD17 clamp loader/9-1-1/TOPBP1 mediator loading at the ssDNA-dsDNA junction. ATR phosphorylates CHEK1 to harness cell cycle arrest. If one-ended DSB is formed, ATM will be activated through the action of the MRE11-RAD50-NBS1 (MRN) complex. ATM mainly phosphorylates CHEK2 to mediate cell cycle arrest. Both ATM and ATR are able to phosphorylate hundreds of proteins in response to DSB formation [57]. One remarkable substrate is the histone H2AX, which can be phosphorylated by both kinases to yield $\gamma$-H2AX. It is conceived that the propagation of $\gamma-\mathrm{H} 2 \mathrm{AX}$ signaling along the chromatin facilitates MDC1 recruitment and BRCA1 signaling via the MDC1-RNF8-RNF168-RAP80 ubiquitin cascade — events that are essential for HR [58].

The repair of TOP1 poison-induced DNA lesions is in essence the repair of one-ended DSBs, which facilitates the restoration of replication forks to restart DNA replication. It is important to note that one-ended DSB repair occurs in the S phase and relies on HR rather than NHEJ [59]. The first step in $\mathrm{HR}$ is end resection to generate a 3 '-overhang for homology searching. A TOP1 cleavage in the leading strand may require end resection by the MRN-CtIP-BRCA1 and BLM-EXO1-DNA2 complexes [60], whereas a cleavage in the lagging strand automatically forms a 3'-overhang. Rad51 then associates with the 3'-ssDNA to form a nucleofilament for strand invasion, which leads to the formation of a D-loop structure [61]. This process continues with DNA synthesis, branch migration and the resolution of Holliday junction structures to reconstitute a functional replication fork [62]. TOP1 poisons can also lead to the formation of two-ended DSB if two replication forks collide into each other at the site of SSB. The repair of this type of DSBs is not aimed for fork restoration and can be accomplished by the classical DSB repair mechanisms [61].

\subsection{Genes Involved in CPT-Induced Damage Repair}

A long list of genes, in which mutations confer sensitivity to CPT in yeast, chicken or mammalian cells, has been compiled [24,30,63]. With no surprise, many genes involved in SSB and DSB repair are on the list, such as PARP1, XRCC1, PNKP, TDP1 for SSB repair; MRN, ATM-CHK2, ATR-CHK1 for DSB signaling; BRCA1/2, XRCC2, XRCC3 for HR. Most recently, the hMSH5-FANCJ complex has also been implicated to play a role in CPT-induced DNA damage response and repair [64]. Mutations in the binding partners of these repair factors are also likely to sensitize cells to CPT treatment. For example, depletion of the MRN-binding partner hnRNPUL increases the sensitivity to CPT [65]; and deficiencies in ZRANB3 and SPIDR, binding partners of PCNA and RAD51, cause CPT hypersensitivity in cancer cells [66-68]. In addition, the two DNA helicases BLM and WRN have also been implicated in the repair of CPT-induced DNA lesions [69,70]. Early studies revealed that chicken BLM knockout cells and human BLM-deficient fibroblasts showed increased sensitivity to CPT $[71,72]$. On the contrary, mouse BLM knockout embryonic stem cells showed mild resistance to 
CPT [73]. This discrepancy is likely attributable to the complexity of CPT-induced DNA lesion repair as well as different treatment conditions and experimental systems.

Interstrand crosslinks (ICLs) resemble CPT-induced lesions in that they block both replication and transcription [74]. They may induce replication fork reversal and fork collapse, which require DNA incision for lesion processing and HR for repair. ICL repair is accomplished by the coordinated actions of 17 Fanconi anemia (FA) genes whose mutations contribute to FA in patients [75]. Depletion of FANCP/SLX4 or FANCQ/XPF causes cellular sensitivity to CPT because they form an endonuclease complex involved in the repair of trapped TOP1cc [38]. Likewise, depletion of FANCS/BRCA1, FANCD1/BRCA2, FANCN/PALB2 or FANCO/RAD51C sensitizes cells to CPT because of their involvement in HR [76]. Accordingly, depletion of the FA core complex except FANCM-involved in fork reversal-is not expected to increase CPT sensitivity because they are unable to recognize the trapped TOP1cc [76]. However, the roles of FANCI, D2, J and FAN1 in the process are elusive due to conflicting reports presumably reflecting different experimental systems [76-78]. For example, in a multicolor competition assay, loss of FANCI or FAN1 rendered cells sensitive to CPT treatment [77]. However, this observation could not be recapitulated in studies performed with FANCI-deficient lymphoblasts and FAN1-depleted HEK293 cells [76,79], indicating that the involvement of these two genes in CTP sensitivity might be cell type specific.

It is interesting to note that the MMS22L-TONSL complex plays a prominent role in mediating CPT sensitivity [80-83]. Depletion of this complex impairs RAD51 foci formation and triggers G2/M arrest, indicating that the MMS22L-TONSL complex participates in HR repair. Furthermore, this complex associates with MCM, FACT, ASF1 and histones. FACT and ASF1 are histone chaperones that function in $\mathrm{H} 2 \mathrm{~A} / \mathrm{H} 2 \mathrm{~B}$ and $\mathrm{H} 3 / \mathrm{H} 4$ chromatin assembly and disassembly, respectively [84]. They recycle parental histones from old DNA strands unwound by MCM and incorporate them into newly synthesized DNA strands. FACT and ASF1 also function in checkpoint signaling; therefore the involvement of MMS22L-TONSL in CPT response implies the existence of a close association between HR, DNA damage signaling and replication restart.

\section{TOP1 Inhibition in Cancer Treatment}

The understanding of the function of TOP1 and the cellular effects of TOP1 inhibition has been a stepping-stone for the development of effective CPT derivatives in cancer therapy. Since TOP1 functions in normal and cancer cells, the use of low doses of TOP1 inhibitors are actively sought to treat cancers that heavily rely on the function of TOP1 for survival (e.g., highly malignant, rapid-dividing tumor cells). In fact, the FDA-approved CPT derivatives topotecan and irinotecan are currently used to treat ovarian and colorectal cancers, respectively [24].

Furthermore, the promising results from a Phase I trial have warranted further evaluation of the CPT derivative Diflomotecan in Phase II trials [85]. Other derivatives like Gimatecan, Lurtotecan and Exatecan are also being tested in clinical trials (Table 1). The non-CPT indolocarbazole BMS-250749 showed great anti-tumor activity against preclinical xenograft models [86], but no further evaluation beyond Phase I trials is presently available (Table 2). Another indolocarbazole compound Edotecarin has shown promising anti-tumor activity in xenograft models and it is now advanced to Phase II studies of patients with advanced solid tumors [87]. By contrast, Phenanthroline ARC-111 (topovale) 
was potently against human tumor xenografts and displayed anti-cancer activity in colon and Wilms' tumors [88]; however, no result from Phase I clinical trials is available owing to profound bone marrow toxicity [89]. To date, indenoisoquinolines are the most promising non-CPT inhibitors in clinical trials. LMP400 (NSC 743400, indotecan) and LMP776 (NSC 725776, indimitecan) show significant anti-tumor activities in animal models and both are being evaluated in Phase I clinical trials for relapsed solid tumors and lymphomas $[8,90]$.

Table 1. CPT derivatives in clinical trials [91].

\begin{tabular}{|c|c|c|c|c|}
\hline Name & Structure & Clinical Trial & Malignancy & Reference \\
\hline Camptothecin & & Discontinued & & [24] \\
\hline $\begin{array}{l}\text { Topotecan } \\
\text { (Hycamtin) }\end{array}$ & & FDA approved & $\begin{array}{l}\text { Ovarian cancer, } \\
\text { SCLC }\end{array}$ & [24] \\
\hline $\begin{array}{c}\text { Irinotecan } \\
(\text { Camptosar/CPT-11) }\end{array}$ & & FDA approved & Colorectal & [24] \\
\hline $\begin{array}{l}\text { Belotecan } \\
(\mathrm{CKD}-602)\end{array}$ & & $\begin{array}{c}\text { Approved } \\
\text { (South Korea) }\end{array}$ & & [4] \\
\hline $\begin{array}{l}\text { Diflomotecan } \\
(\mathrm{BN} 80915)\end{array}$ & & $\begin{array}{c}\text { Phase II } \\
\text { (Ipsen) }\end{array}$ & $\begin{array}{c}\text { Advanced } \\
\text { metastatic cancer, } \\
\text { SCLC }\end{array}$ & [84] \\
\hline $\begin{array}{c}\text { Gimatecan } \\
\text { (ST-1481, LBQ707) }\end{array}$ & & $\begin{array}{l}\text { Phase I/II } \\
\text { (Sigma-Tau, } \\
\text { Novartis) }\end{array}$ & $\begin{array}{l}\text { Advanced solid } \\
\text { tumors }\end{array}$ & [24] \\
\hline $\begin{array}{c}\text { Lurtotecan } \\
\text { (Liposomal OSI-211, } \\
\text { NX 211) }\end{array}$ & & $\begin{array}{c}\text { Phase II } \\
\text { (Astellas, NCLC) }\end{array}$ & SCLC, Ovarian & [24] \\
\hline $\begin{array}{c}\text { Exatecan mesylate } \\
\text { (DX-8951f) }\end{array}$ & & $\begin{array}{c}\text { Phase II/III } \\
\text { (Daiichi) }\end{array}$ & $\begin{array}{c}\text { Sarcoma, } \\
\text { Pancreatic, } \\
\text { Gastric, Liver }\end{array}$ & [24] \\
\hline
\end{tabular}


Given the observation that CPT-mediated TOP1 inhibition provokes DNA repair activities, a synergistic effect is then anticipated on cancer cells by inhibition of TOP1 and downregulation of DNA repair activities. The rationale for this approach is to accelerate the accumulation of DNA breaks and trigger cellular apoptosis, probably through mitotic catastrophe [92]. Which DNA repair pathways can we exploit? Currently, the major interests are in SSB and DSB repair mechanisms. Indeed, PARP inhibitors can enhance the cytotoxicity of TOP1 inhibitors in cancer cell lines as well as in mouse models [93-96]. Phase I studies of combination therapy using PARP inhibitors veliparib or olaparib (FDA-approved) together with topotecan were carried out in patients with advanced solid tumors but showed some dose-dependent side effects [97,98]. TDP1 can be another potential target because it functions directly downstream of PARP1 in the repair of TOP1 poison-induced DNA lesions [99]. TDP1 inhibitors sensitize cells to CPT treatment in vitro [100,101], however in vivo evaluation is presently unavailable due to unsuitable properties of the compounds [102].

Table 2. Non-CPT derivatives in preclinical and clinical trials [91].

\begin{tabular}{|c|c|c|c|c|}
\hline Name & Structure & Clinical Trial & Malignancy & Reference \\
\hline $\begin{array}{l}\text { Indolocarbazoles } \\
\text { (Edotecarin, } \\
\text { BMS-250749) }\end{array}$ & 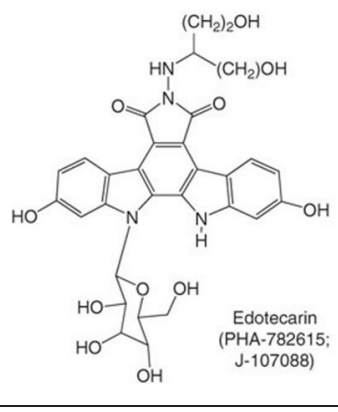 & $\begin{array}{c}\text { Phase II } \\
\text { (Edotecarin, Pfizer) } \\
\text { Preclinical } \\
\text { (BMS-250749) }\end{array}$ & $\begin{array}{l}\text { Stomach, breast } \\
\text { neoplasms } \\
\text { Anti-tumor activity } \\
\text { in preclinical } \\
\text { xenograft models }\end{array}$ & {$[86,87,103]$} \\
\hline $\begin{array}{c}\text { Phenanthridines } \\
\text { (ARC-111/topovale) }\end{array}$ & ARC-111 (topovale) & Preclinical & $\begin{array}{l}\text { Anti-tumor activity } \\
\text { in preclinical } \\
\text { xenograft models }\end{array}$ & {$[88,89,103]$} \\
\hline $\begin{array}{l}\text { Indenoisoquinolines } \\
\text { (LMP400, LMP776) }\end{array}$ & 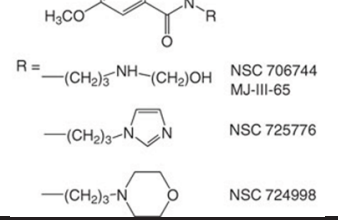 & Phase I & Lymphomas & {$[8,90,103]$} \\
\hline
\end{tabular}

DSB repair can be targeted by either inhibition of DSB signaling or inhibition of HR. ATM and ATR inhibitors can largely increase the sensitivity to CPT in cancer cells [104,105]. This can be explained by the fact that abrogation of the cell cycle arrest will allow cells with unreplicated or unrepaired chromosomes to enter mitosis thereby triggering mitotic catastrophe and cell death. Similarly, CHEK1 and CHEK2 inhibitors are tested in Phase I studies in combination with irinotecan [106,107]. Inhibitors that can directly block HR proteins are very limited [108]. This is partially attributed to the fact that HR genes are often mutated in cancer cells, thus diminishing the enthusiasm for developing HR inhibitors. One diterpenoid compound, however, was found to be able to inhibit the function of BRCA1 and render cytotoxicity in human prostate cancer cells [109]. Several RAD51 inhibitors have also been 
identified but have not been tested in cell lines [110]. Inhibition of BRCA1 and RAD51 can be also achieved indirectly by harnessing corresponding kinases [106]. Clearly, defective hMRE11 sensitizes colon cancer cells to CPT treatment [111]. Although MRE11-deficeint tumor xenografts failed to display significant growth inhibition by irinotecan alone, combining thymidine with irinotecan caused a dramatic growth delay [112].

TOP1 inhibitors might be also useful for treating cancers with BRCA1/2 mutations. The successful use of PARP inhibitors in treating BRCA1/2-deficient tumors has ignited a broad interest in searching for synthetic lethality among DNA damage response and repair genes [113,114]. In the PARP-BRCA1/2 example, the accumulation of SSBs by PARP inhibition would lead to the formation of DSBs during replication. In HR-deficient cells, DSBs can only be repaired by illegitimate (toxic) NHEJ_-joining one-ended DSBs from different locations-leading to cell death [115,116]. However, resistance to PARP inhibitors can arise in BRCA1-deficient tumors during treatment from either genetic reversion of BRCA1 mutations or the loss of NHEJ [117-122]. Therefore, it would be beneficial to explore the possibility of developing a similar synthetic lethal strategy to use TOP1 inhibitors in the treatment of BRCA1/2-deficient tumors.

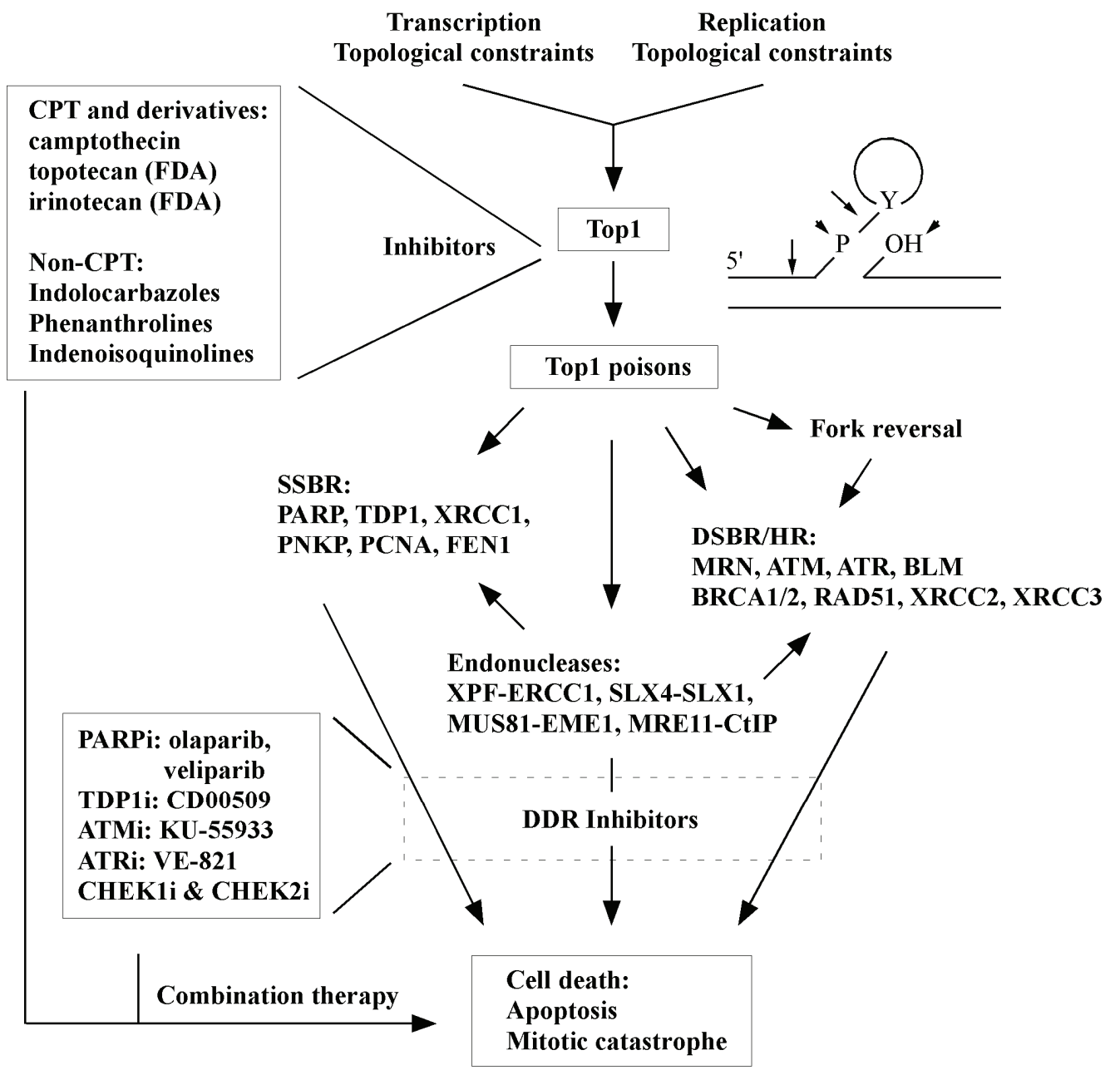

Figure 2. An overview of the effects of TOP1 inhibition is provided. Inhibitors and key DNA repair factors are highlighted. 


\section{Conclusions}

Trapping of TOP1 by inhibitors generates SSBs and DSBs that are repaired by their corresponding repair pathways (Figure 2). Therefore, developing effective TOP1 inhibitors not only provides powerful tools to study DNA replication and repair but also establishes a foundation to devise new synthetic lethal strategies for efficient cancer treatments. The accumulation of DNA strand breaks (SSBs and DSBs) by TOP1 inhibition in HR-deficient tumor cells is expected to enhance cytotoxicity. However, increased DNA repair activities in cancer cells can make TOP1 inhibitors less effective, so silencing of repair pathways in conjunction with the use of TOP1 inhibitors offers an attractive new means for cancer control. Since each tumor is unique, it would be advantageous to identify the individualities of DNA repair pathways or biomarkers reflecting the changes of DNA repair activities in tumor cells [92,123]. This will make it possible to achieve better and predictable prognosis through tailored therapeutic regimens. Given that TOP1 is essential for transcription and DNA replication, future design of novel TOP1 inhibitors and combinational therapy strategies should aim to increase therapeutic efficacy of the inhibitors, thus reducing side effects.

\section{Acknowledgments}

The work in the Her laboratory is supported by the NIH grant GM084353.

\section{Author Contributions}

Yang $\mathrm{Xu}$ and Chengtao Her wrote and revised the article.

\section{Conflicts of Interest}

The authors declare that they have no conflicts of interest with the contents of this article.

\section{References}

1. Helleday, T.; Petermann, E.; Lundin, C.; Hodgson, B.; Sharma, R.A. DNA repair pathways as targets for cancer therapy. Nat. Rev. Cancer 2008, 8, 193-204.

2. Hanahan, D.; Weinberg, R.A. Hallmarks of cancer: The next generation. Cell 2011, 144, 646-674.

3. Branzei, D.; Foiani, M. Maintaining genome stability at the replication fork. Nat. Rev. Mol. Cell Biol. 2010, 11, 208-219.

4. Pommier, Y.; Leo, E.; Zhang, H.; Marchand, C. DNA topoisomerases and their poisoning by anticancer and antibacterial drugs. Chem. Biol. 2010, 17, 421-433.

5. Chu, W.K.; Hickson, I.D. RecQ helicases: Multifunctional genome caretakers. Nat. Rev. Cancer 2009, 9, 644-654.

6. Nitiss, J.L. DNA topoisomerase II and its growing repertoire of biological functions. Nat. Rev. Cancer 2009, 9, 327-337.

7. Nitiss, J.L. Targeting DNA topoisomerase II in cancer chemotherapy. Nat. Rev. Cancer 2009, 9, $338-350$.

8. Pommier, Y. Drugging topoisomerases: Lessons and challenges. ACS Chem. Biol. 2013, 8, 82-95. 
9. Morham, S.G.; Kluckman, K.D.; Voulomanos, N.; Smithies, O. Targeted disruption of the mouse topoisomerase I gene by camptothecin selection. Mol. Cell. Biol. 1996, 16, 6804-6809.

10. Bermejo, R.; Doksani, Y.; Capra, T.; Katou, Y.M.; Tanaka, H.; Shirahige, K.; Foiani, M. Top1- and Top2-mediated topological transitions at replication forks ensure fork progression and stability and prevent DNA damage checkpoint activation. Genes Dev. 2007, 21, 1921-1936.

11. Gambus, A.; Jones, R.C.; Sanchez-Diaz, A.; Kanemaki, M.; van Deursen, F.; Edmondson, R.D.; Labib, K. GINS maintains association of Cdc45 with MCM in replisome progression complexes at eukaryotic DNA replication forks. Nat. Cell Biol. 2006, 8, 358-366.

12. Abdurashidova, G.; Radulescu, S.; Sandoval, O.; Zahariev, S.; Danailov, M.B.; Demidovich, A.; Santamaria, L.; Biamonti, G.; Riva, S.; Falaschi, A. Functional interactions of DNA topoisomerases with a human replication origin. EMBO J. 2007, 26, 998-1009.

13. Merino, A.; Madden, K.R.; Lane, W.S.; Champoux, J.J.; Reinberg, D. DNA topoisomerase I is involved in both repression and activation of transcription. Nature 1993, 365, 227-232.

14. Kharbanda, S.; Rubin, E.; Gunji, H.; Hinz, H.; Giovanella, B.; Pantazis, P.; Kufe, D. Camptothecin and its derivatives induce expression of the c-Jun protooncogene in human myeloid leukemia cells. Cancer Res. 1991, 51, 6636-6642.

15. Tuduri, S.; Crabbe, L.; Conti, C.; Tourriere, H.; Holtgreve-Grez, H.; Jauch, A.; Pantesco, V.; de Vos, J.; Thomas, A.; Theillet, C.; et al. Topoisomerase I suppresses genomic instability by preventing interference between replication and transcription. Nat. Cell Biol. 2009, 11, 1315-1324.

16. Skourti-Stathaki, K.; Proudfoot, N.J. A double-edged sword: R loops as threats to genome integrity and powerful regulators of gene expression. Genes Dev. 2014, 28, 1384-1396.

17. Kobayashi, M.; Aida, M.; Nagaoka, H.; Begum, N.A.; Kitawaki, Y.; Nakata, M.; Stanlie, A.; Doi, T.; Kato, L.; Okazaki, I.M.; et al. AID-induced decrease in topoisomerase 1 induces DNA structural alteration and DNA cleavage for class switch recombination. Proc. Natl. Acad. Sci. USA 2009, 106, 22375-22380.

18. Kobayashi, M.; Sabouri, Z.; Sabouri, S.; Kitawaki, Y.; Pommier, Y.; Abe, T.; Kiyonari, H.; Honjo, T. Decrease in topoisomerase I is responsible for activation-induced cytidine deaminase (AID)-dependent somatic hypermutation. Proc. Natl. Acad. Sci. USA 2011, 108, 19305-19310.

19. Zhang, H.; Zhang, Y.W.; Yasukawa, T.; Dalla Rosa, I.; Khiati, S.; Pommier, Y. Increased negative supercoiling of mtDNA in TOP1mt knockout mice and presence of topoisomerases IIalpha and IIbeta in vertebrate mitochondria. Nucleic Acids Res. 2014, 42, 7259-7267.

20. Douarre, C.; Sourbier, C.; Dalla Rosa, I.; Brata Das, B.; Redon, C.E.; Zhang, H.; Neckers, L.; Pommier, Y. Mitochondrial topoisomerase I is critical for mitochondrial integrity and cellular energy metabolism. PLoS ONE 2012, 7, e41094.

21. Koster, D.A., Palle, K., Bot, E.S., Bjornsti, M.A.; Dekker, N.H. Antitumour drugs impede DNA uncoiling by topoisomerase I. Nature 2007, 448, 213-217.

22. Wall, M.E.; Wani, M.C. Camptothecin and taxol: Discovery to clinic-Thirteenth Bruce F. Cain Memorial Award Lecture. Cancer Res. 1995, 55, 753-760.

23. Pommier, Y. DNA topoisomerase I inhibitors: Chemistry, biology, and interfacial inhibition. Chem. Rev. 2009, 109, 2894-2902.

24. Pommier, Y. Topoisomerase I inhibitors: Camptothecins and beyond. Nat. Rev. Cancer 2006, 6, 789-802. 
25. Fan, Y.; Weinstein, J.N.; Kohn, K.W.; Shi, L.M.; Pommier, Y. Molecular modeling studies of the DNA-topoisomerase I ternary cleavable complex with camptothecin. J. Med. Chem. 1998, 41, 2216-2226.

26. Redinbo, M.R.; Stewart, L.; Kuhn, P.; Champoux, J.J.; Hol, W.G. Crystal structures of human topoisomerase I in covalent and noncovalent complexes with DNA. Science 1998, 279, 1504-1513.

27. Kerrigan, J.E.; Pilch, D.S. A structural model for the ternary cleavable complex formed between human topoisomerase I, DNA, and camptothecin. Biochemistry 2001, 40, 9792-9798.

28. Antony, S.; Jayaraman, M.; Laco, G.; Kohlhagen, G.; Kohn, K.W.; Cushman, M.; Pommier, Y. Differential induction of topoisomerase I-DNA cleavage complexes by the indenoisoquinoline MJ-III-65 (NSC 706744) and camptothecin: Base sequence analysis and activity against camptothecin-resistant topoisomerases I. Cancer Res. 2003, 63, 7428-7435.

29. Sirikantaramas, S.; Yamazaki, M.; Saito, K. Mutations in topoisomerase I as a self-resistance mechanism coevolved with the production of the anticancer alkaloid camptothecin in plants. Proc. Natl. Acad. Sci. USA 2008, 105, 6782-6786.

30. Pommier, Y.; Barcelo, J.M.; Rao, V.A.; Sordet, O.; Jobson, A.G.; Thibaut, L.; Miao, Z.H.; Seiler, J.A.; Zhang, H.; Marchand, C.; et al. Repair of topoisomerase I-mediated DNA damage. Prog. Nucleic Acid Res. Mol. Biol. 2006, 81, 179-229.

31. Desai, S.D.; Li, T.K.; Rodriguez-Bauman, A.; Rubin, E.H.; Liu, L.F. Ubiquitin/26S proteasome-mediated degradation of topoisomerase I as a resistance mechanism to camptothecin in tumor cells. Cancer Res. 2001, 61, 5926-5932.

32. Plo, I.; Liao, Z.Y.; Barcelo, J.M.; Kohlhagen, G.; Caldecott, K.W.; Weinfeld, M.; Pommier, Y. Association of XRCC1 and tyrosyl DNA phosphodiesterase (Tdp1) for the repair of topoisomerase I-mediated DNA lesions. DNA Repair 2003, 2, 1087-1100.

33. Whitehouse, C.J.; Taylor, R.M.; Thistlethwaite, A.; Zhang, H.; Karimi-Busheri, F.; Lasko, D.D.; Weinfeld, M.; Caldecott, K.W. XRCC1 stimulates human polynucleotide kinase activity at damaged DNA termini and accelerates DNA single-strand break repair. Cell 2001, 104, 107-117.

34. Vance, J.R.; Wilson, T.E. Yeast Tdp1 and Rad1-Rad10 function as redundant pathways for repairing Top1 replicative damage. Proc. Natl. Acad. Sci. USA 2002, 99, 13669-13674.

35. Deng, C.; Brown, J.A.; You, D.; Brown, J.M. Multiple endonucleases function to repair covalent topoisomerase I complexes in Saccharomyces cerevisiae. Genetics 2005, 170, 591-600.

36. De Laat, W.L.; Appeldoorn, E.; Jaspers, N.G.; Hoeijmakers, J.H. DNA structural elements required for ERCC1-XPF endonuclease activity. J. Biol. Chem. 1998, 273, 7835-7842.

37. Osman, F.; Whitby, M.C. Exploring the roles of Mus81-Eme1/Mms4 at perturbed replication forks. DNA Repair 2007, 6, 1004-1017.

38. Svendsen, J.M.; Smogorzewska, A.; Sowa, M.E.; O’Connell, B.C.; Gygi, S.P.; Elledge, S.J.; Harper, J.W. Mammalian BTBD12/SLX4 assembles a Holliday junction resolvase and is required for DNA repair. Cell 2009, 138, 63-77.

39. Munoz, I.M.; Hain, K.; Declais, A.C.; Gardiner, M.; Toh, G.W.; Sanchez-Pulido, L.; Heuckmann, J.M.; Toth, R.; Macartney, T.; Eppink, B.; et al. Coordination of structure-specific nucleases by human SLX4/BTBD12 is required for DNA repair. Mol. Cell 2009, 35, 116-127. 
40. Fekairi, S.; Scaglione, S.; Chahwan, C.; Taylor, E.R.; Tissier, A.; Coulon, S.; Dong, M.Q.; Ruse, C.; Yates, J.R., 3rd.; Russell, P.; et al. Human SLX4 is a Holliday junction resolvase subunit that binds multiple DNA repair/recombination endonucleases. Cell 2009, 138, 78-89.

41. Sacho, E.J.; Maizels, N. DNA repair factor MRE11/RAD50 cleaves 3'-phosphotyrosyl bonds and resects DNA to repair damage caused by topoisomerase 1 poisons. J. Biol. Chem. 2011, 286, 44945-44951.

42. Makharashvili, N.; Tubbs, A.T.; Yang, S.H.; Wang, H.; Barton, O.; Zhou, Y.; Deshpande, R.A.; Lee, J.H.; Lobrich, M.; Sleckman, B.P.; et al. Catalytic and noncatalytic roles of the CtIP endonuclease in double-strand break end resection. Mol. Cell 2014, 54, 1022-1033.

43. Wang, H.; Li, Y.; Truong, L.N.; Shi, L.Z.; Hwang, P.Y.; He, J.; Do, J.; Cho, M.J.; Li, H.; Negrete, A.; et al. CtIP maintains stability at common fragile sites and inverted repeats by end resection-independent endonuclease activity. Mol. Cell 2014, 54, 1012-1021.

44. Hiraoka, L.R.; Harrington, J.J.; Gerhard, D.S.; Lieber, M.R.; Hsieh, C.L. Sequence of human FEN-1, a structure-specific endonuclease, and chromosomal localization of the gene (FEN1) in mouse and human. Genomics 1995, 25, 220-225.

45. Zheng, L.; Zhou, M.; Chai, Q.; Parrish, J.; Xue, D.; Patrick, S.M.; Turchi, J.J.; Yannone, S.M.; Chen, D.; Shen, B. Novel function of the flap endonuclease 1 complex in processing stalled DNA replication forks. EMBO Rep. 2005, 6, 83-89.

46. Lin, C.P.; Ban, Y.; Lyu, Y.L.; Liu, L.F. Proteasome-dependent processing of topoisomerase I-DNA adducts into DNA double strand breaks at arrested replication forks. J. Biol. Chem. 2009, 284, 28084-28092.

47. Ray Chaudhuri, A.; Hashimoto, Y.; Herrador, R.; Neelsen, K.J.; Fachinetti, D.; Bermejo, R.; Cocito, A.; Costanzo, V.; Lopes, M. Topoisomerase I poisoning results in PARP-mediated replication fork reversal. Nat. Struct. Mol. Biol. 2012, 19, 417-423.

48. Zellweger, R.; Dalcher, D.; Mutreja, K.; Berti, M.; Schmid, J.A.; Herrador, R.; Vindigni, A.; Lopes, M. Rad51-mediated replication fork reversal is a global response to genotoxic treatments in human cells. J. Cell Biol. 2015, 208, 563-579.

49. Branzei, D.; Foiani, M. Regulation of DNA repair throughout the cell cycle. Nat. Rev. Mol. Cell Biol. 2008, 9, 297-308.

50. Neelsen, K.J.; Lopes, M. Replication fork reversal in eukaryotes: From dead end to dynamic response. Nat. Rev. Mol. Cell Biol. 2015, 16, 207-220.

51. Sogo, J.M.; Lopes, M.; Foiani, M. Fork reversal and ssDNA accumulation at stalled replication forks owing to checkpoint defects. Science 2002, 297, 599-602.

52. Cotta-Ramusino, C.; Fachinetti, D.; Lucca, C.; Doksani, Y.; Lopes, M.; Sogo, J.; Foiani, M. Exo1 processes stalled replication forks and counteracts fork reversal in checkpoint-defective cells. Mol. Cell 2005, 17, 153-159.

53. Thangavel, S.; Berti, M.; Levikova, M.; Pinto, C.; Gomathinayagam, S.; Vujanovic, M.; Zellweger, R.; Moore, H.; Lee, E.H.; Hendrickson, E.A.; et al. DNA2 drives processing and restart of reversed replication forks in human cells. J. Cell Biol. 2015, 208, 545-562.

54. Ciccia, A.; Elledge, S.J. The DNA damage response: Making it safe to play with knives. Mol. Cell 2010, 40, 179-204.

55. Caldecott, K.W. Single-strand break repair and genetic disease. Nat. Rev. Genet. 2008, 9, 619-631. 
56. Cimprich, K.A.; Cortez, D. ATR: An essential regulator of genome integrity. Nat. Rev. Mol. Cell Biol. 2008, 9, 616-627.

57. Matsuoka, S.; Ballif, B.A.; Smogorzewska, A.; McDonald, E.R., 3rd.; Hurov, K.E.; Luo, J.; Bakalarski, C.E.; Zhao, Z.; Solimini, N.; Lerenthal, Y.; et al. ATM and ATR substrate analysis reveals extensive protein networks responsive to DNA damage. Science 2007, 316, 1160-1166.

58. Huen, M.S.; Sy, S.M.; Chen, J. BRCA1 and its toolbox for the maintenance of genome integrity. Nat. Rev. Mol. Cell Biol. 2010, 11, 138-148.

59. Chapman, J.R.; Taylor, M.R.; Boulton, S.J. Playing the end game: DNA double-strand break repair pathway choice. Mol. Cell 2012, 47, 497-510.

60. Symington, L.S.; Gautier, J. Double-strand break end resection and repair pathway choice. Annu. Rev. Genet. 2011, 45, 247-271.

61. Moynahan, M.E.; Jasin, M. Mitotic homologous recombination maintains genomic stability and suppresses tumorigenesis. Nat. Rev. Mol. Cell Biol. 2010, 11, 196-207.

62. Kowalczykowski, S.C. Initiation of genetic recombination and recombination-dependent replication. Trends Biochem. Sci. 2000, 25, 156-165.

63. Maede, Y.; Shimizu, H.; Fukushima, T.; Kogame, T.; Nakamura, T.; Miki, T.; Takeda, S.; Pommier, Y.; Murai, J. Differential and common DNA repair pathways for topoisomerase I- and II-targeted drugs in a genetic DT40 repair cell screen panel. Mol. Cancer Ther. 2014, 13, 214-220.

64. Xu, Y.; Wu, X.; Her, C. hMSH5 facilitates the repair of camptothecin-induced double-strand breaks through an interaction with FANCJ. J. Biol. Chem. 2015, doi:10.1074/jbc.M115.642884.

65. Polo, S.E.; Blackford, A.N.; Chapman, J.R.; Baskcomb, L.; Gravel, S.; Rusch, A.; Thomas, A.; Blundred, R.; Smith, P.; Kzhyshkowska, J.; et al. Regulation of DNA-end resection by hnRNPU-like proteins promotes DNA double-strand break signaling and repair. Mol. Cell 2012, 45, 505-516.

66. Yuan, J.; Ghosal, G.; Chen, J. The HARP-like domain-containing protein AH2/ZRANB3 binds to PCNA and participates in cellular response to replication stress. Mol. Cell 2012, 47, 410-421.

67. Ciccia, A.; Nimonkar, A.V.; Hu, Y.; Hajdu, I.; Achar, Y.J.; Izhar, L.; Petit, S.A.; Adamson, B.; Yoon, J.C.; Kowalczykowski, S.C.; et al. Polyubiquitinated PCNA recruits the ZRANB3 translocase to maintain genomic integrity after replication stress. Mol. Cell 2012, 47, 396-409.

68. Wan, L.; Han, J.; Liu, T.; Dong, S.; Xie, F.; Chen, H.; Huang, J. Scaffolding protein SPIDR/KIAA0146 connects the Bloom syndrome helicase with homologous recombination repair. Proc. Natl. Acad. Sci. USA 2013, 110, 10646-10651.

69. Bernstein, K.A.; Gangloff, S.; Rothstein, R. The RecQ DNA helicases in DNA repair. Annu. Rev. Genet. 2010, 44, 393-417.

70. Croteau, D.L.; Popuri, V.; Opresko, P.L.; Bohr, V.A. Human RecQ helicases in DNA repair, recombination, and replication. Annu. Rev. Biochem. 2014, 83, 519-552.

71. Imamura, O.; Fujita, K.; Itoh, C.; Takeda, S.; Furuichi, Y.; Matsumoto, T. Werner and Bloom helicases are involved in DNA repair in a complementary fashion. Oncogene 2002, 21, 954-963.

72. Rao, V.A.; Fan, A.M.; Meng, L.; Doe, C.F.; North, P.S.; Hickson, I.D.; Pommier, Y. Phosphorylation of BLM, dissociation from topoisomerase IIIalpha, and colocalization with gamma-H2AX after topoisomerase I-induced replication damage. Mol. Cell Biol. 2005, 25, 8925-8937. 
73. Marple, T.; Kim, T.M.; Hasty, P. Embryonic stem cells deficient for BRCA2 or Blm exhibit divergent genotoxic profiles that support opposing activities during homologous recombination. Mutat. Res. 2006, 602, 110-120.

74. Deans, A.J.; West, S.C. DNA interstrand crosslink repair and cancer. Nat. Rev. Cancer 2011, 11, 467-480.

75. Wang, A.T.; Smogorzewska, A. SnapShot: Fanconi anemia and associated proteins. Cell 2015, 160, 354-354.

76. Singh, T.R.; Bakker, S.T.; Agarwal, S.; Jansen, M.; Grassman, E.; Godthelp, B.C.; Ali, A.M.; $\mathrm{Du}$, C.H.; Rooimans, M.A.; Fan, Q.; et al. Impaired FANCD2 monoubiquitination and hypersensitivity to camptothecin uniquely characterize Fanconi anemia complementation group M. Blood 2009, 114, 174-180.

77. Smogorzewska, A.; Desetty, R.; Saito, T.T.; Schlabach, M.; Lach, F.P.; Sowa, M.E.; Clark, A.B.; Kunkel, T.A.; Harper, J.W.; Colaiacovo, M.P.; et al. A genetic screen identifies FAN1, a Fanconi anemia-associated nuclease necessary for DNA interstrand crosslink repair. Mol. Cell 2010, 39, 36-47.

78. Schwab, R.A.; Nieminuszczy, J.; Shin-Ya, K.; Niedzwiedz, W. FANCJ couples replication past natural fork barriers with maintenance of chromatin structure. J. Cell Biol. 2013, 201, 33-48.

79. Kratz, K.; Schopf, B.; Kaden, S.; Sendoel, A.; Eberhard, R.; Lademann, C.; Cannavo, E.; Sartori, A.A.; Hengartner, M.O.; Jiricny, J. Deficiency of FANCD2-associated nuclease KIAA1018/FAN1 sensitizes cells to interstrand crosslinking agents. Cell 2010, 142, 77-88.

80. Duro, E.; Lundin, C.; Ask, K.; Sanchez-Pulido, L.; MacArtney, T.J.; Toth, R.; Ponting, C.P.; Groth, A.; Helleday, T.; Rouse, J. Identification of the MMS22L-TONSL complex that promotes homologous recombination. Mol. Cell 2010, 40, 632-644.

81. O’Connell, B.C.; Adamson, B.; Lydeard, J.R.; Sowa, M.E.; Ciccia, A.; Bredemeyer, A.L.; Schlabach, M.; Gygi, S.P.; Elledge, S.J.; Harper, J.W. A genome-wide camptothecin sensitivity screen identifies a mammalian MMS22L-NFKBIL2 complex required for genomic stability. Mol. Cell 2010, 40, 645-657.

82. O’Donnell, L.; Panier, S.; Wildenhain, J.; Tkach, J.M.; Al-Hakim, A.; Landry, M.C.; Escribano-Diaz, C.; Szilard, R.K.; Young, J.T.; Munro, M.; et al. The MMS22L-TONSL complex mediates recovery from replication stress and homologous recombination. Mol Cell 2010, 40, $619-631$.

83. Piwko, W.; Olma, M.H.; Held, M.; Bianco, J.N.; Pedrioli, P.G.; Hofmann, K.; Pasero, P.; Gerlich, D.W.; Peter, M. RNAi-based screening identifies the Mms22L-Nfkbil2 complex as a novel regulator of DNA replication in human cells. EMBO J. 2010, 29, 4210-4222.

84. Ransom, M.; Dennehey, B.K.; Tyler, J.K. Chaperoning histones during DNA replication and repair. Cell 2010, 140, 183-195.

85. Kroep, J.R.; Gelderblom, H. Diflomotecan, a promising homocamptothecin for cancer therapy. Expert Opin. Investig. Drugs 2009, 18, 69-75. 
86. Saulnier, M.G.; Balasubramanian, B.N.; Long, B.H.; Frennesson, D.B.; Ruediger, E.; Zimmermann, K.; Eummer, J.T.; St. Laurent, D.R.; Stoffan, K.M.; Naidu, B.N.; et al. Discovery of a fluoroindolo[2,3-a]carbazole clinical candidate with broad spectrum antitumor activity in preclinical tumor models superior to the marketed oncology drug, CPT-11. J. Med. Chem. 2005, 48, 2258-2261.

87. Ciomei, M.; Croci, V.; Ciavolella, A.; Ballinari, D.; Pesenti, E. Antitumor efficacy of edotecarin as a single agent and in combination with chemotherapy agents in a xenograft model. Clin. Cancer Res. 2006, 12, 2856-2861.

88. Li, T.K.; Houghton, P.J.; Desai, S.D.; Daroui, P.; Liu, A.A.; Hars, E.S.; Ruchelman, A.L.; LaVoie, E.J.; Liu, L.F. Characterization of ARC-111 as a novel topoisomerase I-targeting anticancer drug. Cancer Res. 2003, 63, 8400-8407.

89. Kurtzberg, L.S.; Battle, T.; Rouleau, C.; Bagley, R.G.; Agata, N.; Yao, M.; Schmid, S.; Roth, S.; Crawford, J.; Krumbholz, R.; et al. Bone marrow and tumor cell colony-forming units and human tumor xenograft efficacy of noncamptothecin and camptothecin topoisomerase I inhibitors. Mol. Cancer Ther. 2008, 7, 3212-3222.

90. Pommier, Y.; Cushman, M. The indenoisoquinoline noncamptothecin topoisomerase I inhibitors: Update and perspectives. Mol. Cancer Ther. 2009, 8, 1008-1014.

91. ClinicalTrials.gov: A service of the U.S. National Institutes of Health. Available online: http://www.clinicaltrials.gov (accessed on 20 June 2015).

92. Bouwman, P.; Jonkers, J. The effects of deregulated DNA damage signalling on cancer chemotherapy response and resistance. Nat. Rev. Cancer 2012, 12, 587-598.

93. Delaney, C.A.; Wang, L.Z.; Kyle, S.; White, A.W.; Calvert, A.H.; Curtin, N.J.; Durkacz, B.W.; Hostomsky, Z.; Newell, D.R. Potentiation of temozolomide and topotecan growth inhibition and cytotoxicity by novel poly(adenosine diphosphoribose) polymerase inhibitors in a panel of human tumor cell lines. Clin. Cancer Res. 2000, 6, 2860-2867.

94. Thomas, H.D.; Calabrese, C.R.; Batey, M.A.; Canan, S.; Hostomsky, Z.; Kyle, S.; Maegley, K.A.; Newell, D.R.; Skalitzky, D.; Wang, L.Z.; et al. Preclinical selection of a novel poly(ADP-ribose) polymerase inhibitor for clinical trial. Mol. Cancer Ther. 2007, 6, 945-956.

95. Patel, A.G.; Flatten, K.S.; Schneider, P.A.; Dai, N.T.; McDonald, J.S.; Poirier, G.G.; Kaufmann, S.H. Enhanced killing of cancer cells by poly(ADP-ribose) polymerase inhibitors and topoisomerase I inhibitors reflects poisoning of both enzymes. J. Biol. Chem. 2012, 287, 4198-4210.

96. Zander, S.A.; Kersbergen, A.; van der Burg, E.; de Water, N.; van Tellingen, O.; Gunnarsdottir, S.; Jaspers, J.E.; Pajic, M.; Nygren, A.O.; Jonkers, J.; et al. Sensitivity and acquired resistance of BRCA1;p53-deficient mouse mammary tumors to the topoisomerase I inhibitor topotecan. Cancer Res. 2010, 70, 1700-1710.

97. Samol, J.; Ranson, M.; Scott, E.; Macpherson, E.; Carmichael, J.; Thomas, A.; Cassidy, J. Safety and tolerability of the poly(ADP-ribose) polymerase (PARP) inhibitor, olaparib (AZD2281) in combination with topotecan for the treatment of patients with advanced solid tumors: A phase I study. Investig. New Drugs 2012, 30, 1493-1500.

98. Kummar, S.; Chen, A.; Ji, J.; Zhang, Y.; Reid, J.M.; Ames, M.; Jia, L.; Weil, M.; Speranza, G.; Murgo, A.J.; et al. Phase I study of PARP inhibitor ABT-888 in combination with topotecan in adults with refractory solid tumors and lymphomas. Cancer Res. 2011, 71, 5626-5634. 
99. Das, B.B.; Huang, S.Y.; Murai, J.; Rehman, I.; Ame, J.C.; Sengupta, S.; Das, S.K.; Majumdar, P.; Zhang, H.; Biard, D.; et al. PARP1-TDP1 coupling for the repair of topoisomerase I-induced DNA damage. Nucleic Acids Res. 2014, 42, 4435-4449.

100. Dean, R.A.; Fam, H.K.; An, J.; Choi, K.; Shimizu, Y.; Jones, S.J.; Boerkoel, C.F.; Interthal, H.; Pfeifer, T.A. Identification of a putative Tdp1 inhibitor (CD00509) by in vitro and cell-based assays. J. Biomol. Screen. 2014, 19, 1372-1382.

101. Fam, H.K.; Walton, C.; Mitra, S.A.; Chowdhury, M.; Osborne, N.; Choi, K.; Sun, G.; Wong, P.C.; O’Sullivan, M.J.; Turashvili, G.; et al. TDP1 and PARP1 deficiency are cytotoxic to rhabdomyosarcoma cells. Mol. Cancer Res. 2013, 11, 1179-1192.

102. Ashour, M.E.; Atteya, R.; El-Khamisy, S.F. Topoisomerase-mediated chromosomal break repair: An emerging player in many games. Nat. Rev. Cancer 2015, 15, 137-151.

103. Dexheimer, T.S.; Pommier, Y. DNA cleavage assay for the identification of topoisomerase I inhibitors. Nat. Protoc. 2008, 3, 1736-1750.

104. Josse, R.; Martin, S.E.; Guha, R.; Ormanoglu, P.; Pfister, T.D.; Reaper, P.M.; Barnes, C.S.; Jones, J.; Charlton, P.; Pollard, J.R.; et al. ATR inhibitors VE-821 and VX-970 sensitize cancer cells to topoisomerase i inhibitors by disabling DNA replication initiation and fork elongation responses. Cancer Res. 2014, 74, 6968-6979.

105. Hickson, I.; Zhao, Y.; Richardson, C.J.; Green, S.J.; Martin, N.M.; Orr, A.I.; Reaper, P.M.; Jackson, S.P.; Curtin, N.J.; Smith, G.C. Identification and characterization of a novel and specific inhibitor of the ataxia-telangiectasia mutated kinase ATM. Cancer Res. 2004, 64, 9152-9159.

106. Curtin, N.J. DNA repair dysregulation from cancer driver to therapeutic target. Nat. Rev. Cancer 2012, 12, 801-817.

107. Garrett, M.D.; Collins, I. Anticancer therapy with checkpoint inhibitors: What, where and when? Trends Pharmacol. Sci. 2011, 32, 308-316.

108. Pearl, L.H.; Schierz, A.C.; Ward, S.E.; Al-Lazikani, B.; Pearl, F.M. Therapeutic opportunities within the DNA damage response. Nat. Rev. Cancer 2015, 15, 166-180.

109. Lin, C.Z.; Zhao, Z.X.; Xie, S.M.; Mao, J.H.; Zhu, C.C.; Li, X.H.; Zeren-dawa, B.; Suolang-qimei, K.; Zhu, D.; Xiong, T.Q.; et al. Diterpenoid alkaloids and flavonoids from Delphinium trichophorum. Phytochemistry 2014, 97, 88-95.

110. Huang, F.; Motlekar, N.A.; Burgwin, C.M.; Napper, A.D.; Diamond, S.L.; Mazin, A.V. Identification of specific inhibitors of human RAD51 recombinase using high-throughput screening. ACS Chem. Biol. 2011, 6, 628-635.

111. Wen, Q.; Scorah, J.; Phear, G.; Rodgers, G.; Rodgers, S.; Meuth, M. A mutant allele of MRE11 found in mismatch repair-deficient tumor cells suppresses the cellular response to DNA replication fork stress in a dominant negative manner. Mol. Biol. Cell 2008, 19, 1693-1705.

112. Rodriguez, R.; Hansen, L.T.; Phear, G.; Scorah, J.; Spang-Thomsen, M.; Cox, A.; Helleday, T.; Meuth, M. Thymidine selectively enhances growth suppressive effects of camptothecin/irinotecan in MSI+ cells and tumors containing a mutation of MRE11. Clin. Cancer Res. 2008, 14, 5476-5483.

113. Farmer, H.; McCabe, N.; Lord, C.J.; Tutt, A.N.; Johnson, D.A.; Richardson, T.B.; Santarosa, M.; Dillon, K.J.; Hickson, I.; Knights, C.; et al. Targeting the DNA repair defect in BRCA mutant cells as a therapeutic strategy. Nature 2005, 434, 917-921. 
114. Bryant, H.E.; Schultz, N.; Thomas, H.D.; Parker, K.M.; Flower, D.; Lopez, E.; Kyle, S.; Meuth, M.; Curtin, N.J.; Helleday, T. Specific killing of BRCA2-deficient tumours with inhibitors of poly(ADP-ribose) polymerase. Nature 2005, 434, 913-917.

115. Bunting, S.F.; Callen, E.; Wong, N.; Chen, H.T.; Polato, F.; Gunn, A.; Bothmer, A.; Feldhahn, N.; Fernandez-Capetillo, O.; Cao, L.; et al. 53BP1 inhibits homologous recombination in BRCA1deficient cells by blocking resection of DNA breaks. Cell 2010, 141, 243-254.

116. Bouwman, P.; Aly, A.; Escandell, J.M.; Pieterse, M.; Bartkova, J.; van der Gulden, H.; Hiddingh, S.; Thanasoula, M.; Kulkarni, A.; Yang, Q.; et al. 53BP1 loss rescues BRCA1 deficiency and is associated with triple-negative and BRCA-mutated breast cancers. Nat. Struct. Mol. Biol. 2010, 17, 688-695.

117. Di Virgilio, M.; Callen, E.; Yamane, A.; Zhang, W.; Jankovic, M.; Gitlin, A.D.; Feldhahn, N.; Resch, W.; Oliveira, T.Y.; Chait, B.T.; et al. Rif1 prevents resection of DNA breaks and promotes immunoglobulin class switching. Science 2013, 339, 711-715.

118. Zimmermann, M.; Lottersberger, F.; Buonomo, S.B.; Sfeir, A.; de Lange, T. 53BP1 regulates DSB repair using Rif1 to control 5' end resection. Science 2013, 339, 700-704.

119. Chapman, J.R.; Barral, P.; Vannier, J.B.; Borel, V.; Steger, M.; Tomas-Loba, A.; Sartori, A.A.; Adams, I.R.; Batista, F.D.; Boulton, S.J. RIF1 is essential for 53BP1-dependent nonhomologous end joining and suppression of DNA double-strand break resection. Mol. Cell 2013, 49, 858-871.

120. Escribano-Diaz, C.; Orthwein, A.; Fradet-Turcotte, A.; Xing, M.; Young, J.T.; Tkac, J.; Cook, M.A.; Rosebrock, A.P.; Munro, M.; Canny, M.D.; et al. A cell cycle-dependent regulatory circuit composed of 53BP1-RIF1 and BRCA1-CtIP controls DNA repair pathway choice. Mol. Cell 2013, 49, 872-883.

121. Xu, G.; Chapman, J.R.; Brandsma, I.; Yuan, J.; Mistrik, M.; Bouwman, P.; Bartkova, J.; Gogola, E.; Warmerdam, D.; Barazas, M.; et al. REV7 counteracts DNA double-strand break resection and affects PARP inhibition. Nature 2015, 521, 541-544.

122. Boersma, V.; Moatti, N.; Segura-Bayona, S.; Peuscher, M.H.; van der Torre, J.; Wevers, B.A.; Orthwein, A.; Durocher, D.; Jacobs, J.J. MAD2L2 controls DNA repair at telomeres and DNA breaks by inhibiting 5 ' end resection. Nature 2015, 521, 537-540.

123. Ogino, S.; Fuchs, C.S.; Giovannucci, E. How many molecular subtypes? Implications of the unique tumor principle in personalized medicine. Expert Rev. Mol. Diagn. 2012, 12, 621-628.

(C) 2015 by the authors; licensee MDPI, Basel, Switzerland. This article is an open access article distributed under the terms and conditions of the Creative Commons Attribution license (http://creativecommons.org/licenses/by/4.0/). 